Iker Zulaica Hernández*

\title{
Resolving abstract anaphors in Spanish discourse: Underspecification and mereological structures
}

https://doi.org/10.1515/ling-2018-0008

\begin{abstract}
Anaphoric underspecification involves multiple potential candidate antecedents for an anaphoric expression. In abstract object anaphora, where linguistic antecedents are clauses, sentences and larger fragments of discourse, the source of referential underspecification is commonly found at the propositional level. Thus, underspecified abstract anaphors have multiple antecedents of a higher-order nature (i.e., propositions and events). Following previous research on anaphoric underspecification with nominal antecedents, I propose a hypothetical three-step process toward the resolution of underspecified abstract object anaphors by hearers in discourse: (i) creation of a complex abstract object with a mereological structure that includes all potential interpretations for an anaphor, (ii) recognition of the thematic connection among propositions intended by the speaker in the form of a specific rhetorical relation, and 3) resolution of the abstract anaphor. Potential antecedents for any underspecified abstract anaphor may include atomic propositions and complex abstract referents that result from a merged interpretation of several propositions that are thematically connected. Provided that it is available, I claim that such a merged interpretation, which is part of the mereological structure, is the preferred interpretation as it is generally interpreted as part of a general purpose by the speaker, in addition to contributing to the thematic coherence of discourse.
\end{abstract}

Keywords: underspecification, anaphora, mereology, rhetorical structure, reference

\section{Introduction}

In natural languages, vagueness, ambiguity, and underspecification are common at different levels of meaning: lexical, scopal, or anaphoric ambiguity,

*Corresponding author: Iker Zulaica Hernández, Department of World Languages and Cultures, Indiana University-Purdue University, 425 University Blvd., Indianapolis, Indiana 46202, USA, E-mail: izulaica@iupui.edu 
among others. ${ }^{1}$ As a semantic interpretation process, anaphora is subject to referential underspecification when more than one candidate referent is available for a given anaphoric expression such as a pro-form, a definite noun phrase, or a proper noun. ${ }^{2}$

Underspecification involving anaphoric expressions has been widely investigated from a variety of theoretical standpoints and methodologies. Poesio et al.'s (2005) Justified Sloppiness has received much attention in the literature on anaphoric underspecification recently. In short, this hypothesis claims that hearers resolve ambiguous anaphoric expressions more easily when potential antecedents of ambiguous expressions are part of an underlying mereological structure with parts and subparts. Consider example (1). The pronoun it in the second sentence is underspecified, and mereological, because it can anaphorically corefer with the individual referents 'the apartment', 'the storage room', but also with the complex antecedent an apartment with a storage room, that results from merging the apartment and the storage room into a single complex referent. A basic ontology is therefore assumed whereby individual referents would be treated as atomic elements, and complex referents such as an aptment with a storage room sums of its individual parts, or as sets of atoms in a mereological structure.

(1) John bought $[\text { [an apartment }]_{i}$ with $\left.[\text { a storage room }]_{j}\right]_{i+j}$ recently. One year later, he sold $i_{i / j / i+j}$ to Mary for twice its original value.

However, while most studies on anaphoric underspecification have focused on the resolution of pro-forms with nominal antecedents, less attention has been paid to discourse anaphora involving clausal antecedents. ${ }^{3}$ It is widely acknowledged that clausal antecedents commonly denote higher-order entities such as events or propositions. Following previous accounts on abstract object anaphora (Webber 1979; Webber 1988; Asher 1993; Dipper and Zinsmeister 2012; inter

1 See Pinkal (1996) for an excellent investigation on linguistic ambiguity.

2 Although anaphora and coreference are intimately related they are different phenomena. In this paper and in order to simplify the discussion, I intentionally conflate both phenomena (1. a relation of interpretative dependency between an antecedent (of any kind) and a proform, and 2. a relation of interpretative dependency between two NPs) under the label 'anaphora'. Also, I will not be making a distinction between surface anaphora and deep anaphora; see Hankamer and Sag (1976) for details.

3 While many studies put the focus mainly on abstract anaphora annotation (see Byron 2003; Navarretta and Olsen 2009; Poesio and Artstein 2008; Recasens and Martí 2010), many others have proposed resolution systems for abstract antecedents (Byron 2002; Eckert and Strube 2000; Müller 2008; Schuster 1986; and references therein). 
alia), I assume that discourse segments (clauses, sentences, and groups of sentences) can denote semantic entities of an abstract nature, and that these abstract entities can be referred to anaphorically with discourse anaphors such as pro-forms and definite NPs. ${ }^{4}$ A case of anaphoric underspecification involving abstract antecedents is shown in (2). The discourse has been segmented into its constituent clauses, which have been labeled and numbered consecutively $\left(\pi_{1} . . \pi_{n}\right)$ to facilitate the analysis. The notation $\mathrm{K} \pi_{\mathrm{n}}$ represents the proposition denoted by each utterance.

(2) $\pi_{1}$ : A uno de los empleados se le negó el ascenso tres veces. $\quad K \pi_{1}$ 'One of the employees was denied a promotion three times.'

$\pi_{2}$ : A otro no se le subió el sueldo durante cinco años.

$K \pi_{2}$ 'Another one didn't get a raise for five years.'

$\pi_{3}$ : A un tercero se le pagaba menos sueldo que al resto de sus $\mathrm{K}_{3}$ compañeros.

'A third one was paid a lower salary than the rest of his colleagues.'

$\pi_{4}$ : Pero el magistrado no vió en aquello suficiente prueba de delito. $K \pi_{4}$ 'But the judge did not see any offense in that.'

The pronoun aquello in the last utterance $\pi_{4}$ is underspecified insofar as it may refer to each proposition $\mathrm{K} \pi_{1}, \mathrm{~K} \pi_{2}, \mathrm{~K} \pi_{3}$ individually, or to the result of merging those propositions into a complex abstract antecedent. The discourse particle pero 'but' in $\pi_{4}$ suggests a contrast with some previous statement. Following Blakemore (2002: 33), for whom the particle but has the cognitive effect of contradiction and elimination, the relevance of segment $\pi_{4}$ lies in its ability to contradict and eliminate an assumption inferred by the hearer from the previous discourse. Thus, the contrastive particle would force the hearer to go back in discourse in order to contradict and eliminate an inferred assumption in what Blakemore dubbed backtracking.

In order to resolve the underspecification, the hearer should first resolve the proposition that triggers the assumption that the discourse particle is supposed to contradict: does proposition $\mathrm{K}_{4}$ establish a contrast with an individual

4 The abstract object semantic ontology distinguishes states from events, and different types of eventualities based on their different semantics, i.e., accomplishments, achievements, and activities (Vendler 1967). Also, Asher (1993) argues that facts can be distinguished from events based on their varying degree of world immanence (Asher 1993). I will not apply such finegrained distinction in this paper and I will limit the ontology to a more basic distinction: propositions and events. 
proposition -any of those preceding $\mathrm{K}_{4^{-}}$or with the complex abstract referent that results from combining propositions $K \pi_{1}-K \pi_{3}$ ? It looks like discourse (2) is doubly underspecified: (i) the underspecification originating from the anaphor and (ii) the one originating from the contrastive particle pero. In the most natural interpretation though, the anaphor aquello 'that' would refer to the complex abstract referent that results from merging propositions $\mathrm{K} \pi_{1}$ through $\mathrm{K} \pi_{3}$, and the assumption inferred and subject to contrast by the particle pero will result from this merged interpretation.

The main goal of this paper is to offer a plausible hypothesis to the question of how hearers infer merged interpretations from sequences of individual utterances; in other words, how hearers infer merged complex abstract referents. I argue that complex abstract referents can be conceived of as superpropositions resulting from summing or merging individual propositions through a process of propositional integration. I claim that propositional integration processes are theoretically plausible and descriptively adequate since discourses appear to be made of subcomponents (i.e., constituent or atomic propositions), and show a granularity similar to the one proposed in the Justified Sloppiness Hypothesis for mereological nominal referents.

However, simply claiming that the propositional content of discourse can be merged to form structured and complex abstract referents through some sort of mereological process is not fully satisfactory. Any account of underspecification of propositional content will require a plausible explanation of how atomic elements can be integrated into larger thematic units, and of how language speakers make sense of apparently disconnected utterances without overt discourse particles that may facilitate thematic connections; a situation that is fairly common in written and spoken discourse. Thus, while the preposition with (and possibly world knowledge) in (1) works as a clear indicator for hearers to construct the complex antecedent apartment with $a$ storage room made of subparts apartment and storage room, inferring a mereological interpretation for abstract antecedents can be a far more difficult task due to the general lack of explicit grammatical clues in the text. Furthermore, our notion of mereological structure has to be complete enough to include the preferred complex abstract referent plus all other potential interpretations for the anaphor.

This paper investigates anaphoric underspecification involving complex abstract referents in Spanish discourse. My main claim is that hearers infer complex abstract referents through a process of propositional integration that yields thematically coherent discourse units. I propose a three-step process in resolving abstract anaphors that involve propositional material. I hypothesize that these steps must occur in the following order: 


\section{Resolution of Underspecified Abstract Anaphors:}

i. In the first step, a mereology construction process takes place whereby hearers create a complex abstract object with mereological structure (i.e., having a summum and subparts) that includes the preferred interpretation, plus any additional potential interpretations. This complex abstract object is a set that includes all potential individual referents (atomic propositions) and any potential summum (complex abstract referents) that results from merging atomic propositions into larger propositional units.

ii. The hearer then proceeds to infer rhetorical connections among the propositions in the complex abstract object. If a suitable and meaningful rhetorical connection can be established among atomic propositions, that will be the preferred interpretation. Otherwise, the hearer goes back to the complex abstract object (the set) to find a preferred interpretation within the mereological structure.

iii. The abstract anaphor is resolved once the most suitable interpretation is chosen from the set. The most suitable and preferred interpretation will be the most acceptable antecedent in anaphoric processes (or the referent in co-referential processes).

The cognitive process of creating a complex abstract object takes place at the propositional level. In line with the mereological structure proposed for nominal referents in the Justified Sloppiness Hypothesis, my claim is that complex abstract objects also have a mereological structure with a summum and subparts (i.e., super events are made up of constituent sub-events; super propositions are made up of constituent propositions). This structure will account for the preferred interpretation as well as for all other potential interpretations of the underspecified anaphor. As I said, my representation of the hypothetical complex abstract object with mereological structure is a set $\Sigma=\left\{K \pi_{1}, K \pi_{2}, K \pi_{n}\right.$, $\left.\oplus \mathrm{K} \pi_{1} . . \mathrm{K} \pi_{\mathrm{n}}\right\}$ that includes, as potential referents, individual atomic propositions $\mathrm{K} \pi_{1} . . \mathrm{K} \pi_{\mathrm{n}}$ and complex referents made of sums of atomic propositions represented with the symbol $\oplus$. Next, the hearer will choose the most suitable antecedent from the complex abstract object. The hearer will proceed to infer a thematic link among the propositions in the mereological structure. This link will be explained following the framework of Segmented Discourse Representation Theory (Asher and Lascarides 2003). This theory proposes that rhetorical relations such as Narration, Continuation, Explanation, etc., glue the propositional material of discourse to form cohesive and coherent discourses. Therefore, the rhetorical connection among utterances is an essential step for hearers to resolve ambiguous anaphoric expressions. 
Returning to example (2), its rhetorical structure is shown in (4), where $R R$ stands for the rhetorical relation among propositions in the mereological structure. A relation of Continuation (RR1) holds among propositions $\mathrm{K} \pi_{1}$ and $\mathrm{K} \pi_{2}$, and also between proposition $K \pi_{3}$ and the complex referent $K \pi_{1-2}$ (i.e., $\oplus K \pi_{1}-K \pi_{2}$ in mereological notation). From the incremental continuation of propositions $\mathrm{K} \pi_{1}$ through $\mathrm{K} \pi_{3}$ the hearer infers a discourse topic. A relation of Contrast (RR3) holds between proposition $\mathrm{K}_{4}$ and the common topic of the discourse. Upon processing the discourse, the hearer would interpret propositions $\mathrm{K} \pi_{1}, \mathrm{~K} \pi_{2}$ and $\mathrm{K} \pi_{3}$ as a single thematic unit (i.e., a complex abstract referent $\oplus \mathrm{K} \pi_{1}-\mathrm{K} \pi_{3}$ ), and infer the assumption that will later be contrasted upon processing the contrastive particle in the last sentence. The complex abstract referent is the preferred interpretation that resolves the underspecified demonstrative anaphor.

(4) RR1: $K \pi_{2}$ Continuation $K \pi_{1}$

RR2: $K \pi_{3}$ Continuation $K \pi_{1-2 \text { Continuation }}$

RR3: $K \pi_{4}$ Contrast $K \pi_{1-2-3 D i s c o u r s e \_t o p i c}$

Although the inventory of rhetorical relations is varied in SDRT, some specific relations contribute better than others in creating thematic units. Thus, coordinating relations such as Narration or Continuation require a topic that may have been explicitly mentioned in the discourse or, otherwise, it has to be constructed. As it will be explained in detail in section 4, the topic in SDRT results from thematic discourse integration at the propositional level and, in my view, discourse topics find an analogue in the summum interpretation proposed for nominal antecedents in the Justified Sloppiness Hypothesis.

In summary, not only are mereological structures and rhetorical-relation inferential processes compatible, but they are also needed to explain the construction of complex abstract referents. Furthermore, rhetorical relations are also advantageous insofar as they can explain how discourse segments link up semantically despite their sometimes apparent disconnection due to common textual disruptions, interruptions in the flow of discourse, and to the lack of explicit connecting words.

\section{Discourse segments, abstract referents, and collective reference}

In this section, the theoretical adequacy of abstract objects as true referents in anaphoric processes, and the availability of mereological processes involving 
these objects are discussed. The status of eventualities as referents for anaphoric pronouns is generally accepted in the field of anaphora studies today; however, the status of propositions as available referents in a discourse model is controversial. In his seminal work on reference to abstract objects, Asher takes a stand by taking discourse segments as denoting propositions, and propositions as terms to discourse relations. In his theory of discourse structure, propositional constituents do actually function as the referents for pronouns in anaphoric connections that involve discourse segments as linguistic antecedents (1993: 4).

Asher makes a preliminary distinction between eventuality anaphora, and abstract anaphora. This distinction is made on the basis of the denotational differences between eventualities and more abstract objects such as propositions, facts, or states of affairs. For Asher, sentential nominals, verb phrases, sentences, and even sequences of sentences may furnish antecedents to pronouns in discourse, which makes problematic sometimes to tell whether a particular sentence denotes an eventuality, a proposition, or both. In (5), for example, the pronoun it seems to refer to a kicking event, whereas the reference of the pronoun that in (6) may be in dispute among an eventuality, a proposition, or a fact. ${ }^{5}$ He argues that abstract objects are gradable based on their causal, temporal and spatial properties, and he proposed a spectrum of world immanence ranging from more immanent objects like events and states to purely abstract objects such as propositions.

(5) John kicked Sam on Monday, and it $_{i}$ hurt.

(6) Be careful what you wish ... because wishes sometimes come true. That's what the Semiconductor Industry Association, which represents U.S. manufacturers, has been learning.

However, as I said, propositional anaphora, or anaphora at the clausal level and beyond, is still controversial mainly because of the nature of propositions: they do not occur in time or space like events, and they are purely mental objects. Reference to discourse segments, or to the entities denoted by such segments, has been a subject of debate since the late 80's. In the computation of discourse meaning, segments have long been recognized as having interesting referring properties, and being available as discourse referents. Webber was one the first authors to explore discourse segmentation, and anaphoric reference to discourse segments via deictic expressions, a phenomenon she dubbed discourse deixis. As

5 Examples (5)-(6) are from Asher (1993). 
she points out (1988: 3), "There is ample evidence that subsequent reference can be made to some aspect of a sequence of clauses in text. Therefore, the existence of such a phenomenon is not in dispute. Also not in dispute is the fact that such subsequent reference is most often done via deictic pronouns. Because of this I will call this type of reference discourse deixis." Later on, she suggests that a text is more than a simple sum of its component sentences, and that the source of additional meaning stems from relations that hold among adjacent sentences "syntactically connected within a larger discourse structure". (2003: 1). ${ }^{6}$

Webber starts by making an important distinction between discourse entities, akin to Karttunen's (1976) discourse referents, and discourse segments. ${ }^{7}$ She attributes a distinct mental reality to discourse segments and, therefore, reference to discourse entities and reference to discourse segments should be accounted for as different types of reference. Reference to discourse entities would explain anaphoric and definite reference (discourse entities go with NPs for the author), whereas reference to discourse segments would explain textual coherence and discourse structure (discourse segments go with sentences and clauses). In essence, Webber's proposal entails that reference to discourse segments must be considered a different phenomenon from the type of anaphoric reference that holds between a pronoun and a discourse entity insofar as, crucially, the referent in discourse deixis processes is often distinct from the things described in the sequence: "a separate reference ${ }_{m}$ process by which a linguistic expression is first interpreted as a pointer to the representation of a discourse segment, and then further constrained to specify either (a) a particular aspect of the discourse segment (e.g., its form, interpretation, speech act) or (b) a particular entity within its interpretation." (1988: 3) Two houses are described

6 Following Webber's seminal work, discourse segmentation and discourse deixis has been applied to many studies on anaphora cross-linguistically. For example, Artstein and Poesio (2006) conducted a study aimed to identify reference to abstract objects in dialogue. In their study, their annotators marked antecedents for discourse deixis as unconstrained regions of text, showing a high degree of inter-annotator agreement on the identity of segment antecedents. Recasens et al. (2007: 209), working on their ideas on text as scene, also acknowledge the possibility of reference to fuzzy antecedents assuming that their type can be event, proposition and fact depending on the predicate complement information. As these authors point out: "we consider an anaphoric NP to be in a discourse deictic relation when its antecedent is a textual scene expressed by a clause or a sequence of clauses. NPs that have the potential to participate in discourse deixis links are demonstrative pronouns, the neuter personal pronoun lo, the relative pronoun que, demonstrative full NPs, and definite descriptions."

7 Discourse segments have been defined differently in the literature: as a chunk of text that expresses a common purpose with respect to the speaker's plan (Grosz and Sidner 1986); as a chunk of text that has a common meaning (Hobbs et al. 1993); or as a chunk of text that describes a single event from a single perspective in narratives (Nakhimovsky 1988). 
in discourse (7) (from Webber 1988). The demonstrative pronouns in this text do not refer to the houses themselves, but to the descriptions of the houses. Furthermore, the demonstrative in the last sentence appears to refer to the two descriptions altogether, which is, in my view, an implicit assumption that individual segments can merge into larger units, and be subsequently referred to. An experiment made by Webber consisting of brief discourses and demonstrative pronouns seems to confirm this idea as the results indicate that the participants interpreted those pronouns either as referring to the individual preceding segment, or to the combination of the two previous segments.

(7) House A is in Palo Alto. It's got three bedrooms and two baths, and was built in 1950. It's on a quarter acre, with a lovely garden, and the owner is asking $\$ 425 \mathrm{~K}$. But that's all I know about it.

House $B$ is in Portola Valley. It's got 3 bedrooms, 4 baths and a kidneyshaped pool, and was also built in 1950. It's on 4 acres of steep wooded slope, with a view of the mountains. The owner is asking $\$ 600 K$. I heard all this from a friend, who saw the house yesterday.

Is that enough information for you to decide which to look at?

But what is a discourse segment? Segments can have precise boundaries (sentences, clauses), but they can also be discontinuous structures (see Artstein and Poesio 2006). Intuitively, cohesion and coherence seem to play an important role in determining what a segment is. The pronoun that in (8), according to Webber, may be taken to refer to the narrative of the glaciers and the Folsum men (consisting of several utterances), "which is intuitively a coherent discourse segment.” (1988: 4)

(8) It's always been presumed that ${ }_{1}$ when the glaciers receded, the area got very hot. The Folsum men couldn't adapt, and they died out.] That's what is supposed to have happened. It's the textbook dogma. But it's wrong. They were human and smart. They adapted their weapons and culture, and they survived.

However, Webber does not take a stand with regard to the true status of discourse segment referents, or whether they can be considered discourse entities like the referents of NPs. She argues that there is no precise criterion for 'discourse entity-hood', and not enough evidence to warrant taking a stand on the subject. At the same time though, she does not deny the possibility that the referent evoked by a discourse segment can be a 'normal' discourse entity when she comments (1988: 7): "Suppose one assumes that the ability to specify something via an anaphoric pronoun is sufficient criterion for "discourse 
entity-hood". Then I would claim that whether or not a discourse segment referent is initially created as a discourse entity, once the speaker has successfully referred to it via 'this/that', it must now have the status of a discourse entity since it can be referenced via the anaphoric pronoun it."

Following previous work on the domain of events, Asher elaborates on the summation principles for events and propositions. He argues that events can be summed to yield new events, but he acknowledges that there are differences with summation in the domain of individuals. ${ }^{8}$ For example, a sum of events cannot be referred to with a plural pronoun in the way a sum of individuals can. The plural pronoun they in (9) can only refer to the group of three individuals that raised the flag, and never to the group of three 'flag-raising' events. Conversely, the pronoun it can refer to the group of events. This restriction of plural pronominal reference to sums of events would make event expressions similar to mass nouns. ${ }^{9}$

(9) Three men raised ${ }_{i}$ the flag of the republic. ${ }^{*}$ They $_{i} /$ it $_{i} /$ those events $_{i}$ took the ruling junta by surprise.

However, Asher observed that the collection of events can also be referred to with the noun phrase those events, and based on this observation he argues that there may be two ways of forming collections of events, "a principle that takes individual events and fuses them into larger individual events (the mass-like summation principle), and a principle that takes individual events and forms a plural group from them (the 'count' summation principle).” (1993: 43) But crucially, events have to be thematically connected to form a whole event that can be subsequently referred to with a pronoun. In other words, not every group of events can be summed together. Asher explains that only events of the same type can naturally connect, and they do connect via paths, that is, via causal and temporal relations. Thus, these paths connect events in stereotypical sequences that are part of the common sense knowledge of a competent speaker, and are used in text interpretation.

With regard to propositions, Asher argues that their domain also has a structure. He found striking coincidences between the domain of events and the domain of propositions, which seems to indicate that both domains share similar

8 The view that events in natural language metaphysics are a structured domain closed under a join or sum operation is shared by Link (1983) and Ter Meulen (1984), among others.

9 There are alternative ways of dealing with relationships among events. In WordNet (Vossen 1998), for example, meronymic relations mostly hold among physical objects. Although WordNet and EuroWordNet assume Lyons' (1977) ontology of semantic types (1st, 2nd and 3rd order entities), relations between verbs in this framework are mainly based on entailment (temporal inclusion, overlap, backward presupposition, and causality). 
summation principles. Let's consider example (10). The pronoun 'it' seems to refer to the proposition that combines all that Mary says (a sum), and the plural noun phrase 'these claims' can also be used with the same reference. ${ }^{10}$

(10) John believes everything Mary says. Further, it is all true.

Also, utterances in a text may combine to form a proposition that is the anaphoric referent of a pronoun or definite description, as in (11).

(11) The liberation of the village had been bloody. [Some of the Marines had gone crazy and killed some innocent villagers. To cover up the "mistake", the rest of the squad had torched the village, and the lieutenant called in an air strike. $]_{i}$ At first the battalion commander hadn't believed it . $_{\text {. }}$

In this paper, I assume that higher-order entities like events and propositions can be merged into complex abstract objects following Asher's (1993) proposal. Potential antecedents for an underspecified abstract anaphor may thus include atomic propositions and complex abstract referents that may result from a merged interpretation of an unspecified number of thematically connected propositions. If it is available, I claim that this merged interpretation, which is part of a mereological structure, is the preferred interpretation insofar as it is generally interpreted as part of a general purpose by the speaker, in addition to contributing to the thematic coherence of discourse.

\section{Mereological structures and the Justified Sloppiness Hypothesis}

In essence, mereology has to do with parts, and with the relations of part to a whole, as well as the relations of part-to-part in the whole. As it is customary in philosophical studies, no ontological restrictions on the notion of part will be assumed in this paper (events, spatio-temporal regions, geometric objects, kinds, propositions, properties, and so forth, can be parts); however, this investigation will focus entirely on abstract entities such as propositions and events. In this line, propositions and events will be taken as atoms or atomic elements in the mereology, that is, propositions and events are entities with no proper parts. ${ }^{11}$

10 Examples (9)-(11) are from Asher (1993).

11 See Ojeda (1993) for a detailed study on the semantic structure of linguistic individuals. 
Elaborating on psycholinguistic research on the interpretation of polysemy and homonymy, Poesio et al. (2005) investigated cases of underspecified anaphoric expressions that do not seem to have a preferred antecedent, yet they are resolved by hearers without any apparent misunderstanding. An example of underspecified anaphoric pronoun with noun phrase antecedents is shown in the following short dialogue from the TRAINS corpus (Gross et al. 1993) in (12). ${ }^{12}$ Here, the pronoun it (repeated several times in the dialogue) is underspecified since it can corefer either with the engine E2 that has been hooked up to the boxcar at Elmira, or with the boxcar itself (both underlined in utterance 3.3). Evidence that the pronoun refers to the boxcar at Elmira is given in utterance 9.5 since, as the authors explain: "it is only boxcars that can be filled with oranges." (2005: 4)

These and similar cases are referred to by Poesio et al. as mereological cases, and their corresponding pronouns (i.e., the pronoun it in (1) and in (12)) as mereological pronouns. Mereological pronouns have special properties insofar as they can receive a merged interpretation, that is, an interpretation that brings together the two possible antecedents in (12). The merged interpretation would result from combining the engine and the boxcar into a single referent: the train formed by the engine and the boxcar.

(12) 3.1 M: can we .. kindly hook up

3.2 uh

3.3 engine E2 to the boxcar at .. Elmira

4.1 S: ok

5.1 M: +and+ send it to Corning

5.2 as soon as possible please

6.1 S: okay

7.1 M: do let me know when it gets there

8.1 S: okay it'll /

8.2 it should get there at $2 A M$

9.1 M: great

9.2 uh can you give the

9.3 manager at Corning instructions that

9.4 as soon as it arrives

9.5 it should be filled with oranges

10.1 S: okay

10.2 then we can get that filled

12 This example is from Poesio et al. (2005). 
In order to explain how such pronouns are resolved, the authors examined whether sentences that contained an ambiguous anaphor are easier to process when the two (or more) potential antecedents are part of a mereological structure. This condition was compared to a second condition in which the two antecedents cannot be merged. The results of their investigation revealed that mereological sentences such as (13a) were perceived by subjects more acceptable than non-mereological ones (13b). The authors concluded that these differences were due to the anaphoric content of the sentences, and they interpreted these processing difference in terms of the perceived difficulty associated with referential ambiguity in the nonmereological case (13b).

(13) a. The engineer hooked up the engine to the boxcar and sent it to London.

b. The engineer separated the engine from the boxcar and sent it to London.

In an eye-tracking study, Filik et al. (2005) tested the online processing of anaphoric reference to mereological structures. The subjects were given a set of sentences with mereological constructing predicates (i.e., hook up) and with neutral predicates (i.e., saw) and singular and plural pronouns, as in (14a)-(14d). ${ }^{13}$ Their prediction was that mereological structures such as (14a) and (14b) would make alternative interpretations available for singular pronouns thus eliminating the so-called conjunction cost in complex reference objects; where conjunction cost is the difficulty in processing caused by singular pronouns being forced to refer to a single conjunct in a coordinated noun phrase structure (see also Albrecht and Clifton 1998; Moxey et al. 2004).

(14) a. Mereological predicate+singular anaphor

There were many delays. The railway man hooked up the engine and the boxcar, and sent it quickly to the central station.

b. Mereological predicate+plural anaphor

There were many delays. The railway man hooked up the engine and the boxcar, and sent them quickly to the central station.

13 Mereology-constructing predicates are predicates that force a merged interpretation of their arguments. For example, the predicate hook up coerces the interpretation where the hooked up elements are conceived of as forming a single object; a summum in Poesio et al.'s terminology. 
c. Neutral predicate+singular anaphor

There were many delays. The railway man saw the engine and the boxcar, and sent it quickly to the central station.

d. Neutral predicate+plural anaphor

There were many delays. The railway man saw the engine and the boxcar, and sent them quickly to the central station.

The results of their study appear to confirm their initial prediction that singular reference was easier in mereological than in neutral sentences. Based on experimental evidence, Poesio et al. offered an interpretation for mereological pronouns following the theory of plurals and parts developed by Link (1983). They claimed that underspecified pronouns are more easily resolved because their antecedents are part of an underlying mereological structure that "makes it possible for the hearer to construct a p-underspecified interpretation in which the anaphoric expression is interpreted as denoting an element $z$ included in the mereological structure; i.e., part of its summum.” (Poesio et al. 2005: 11) In this line, they propose four possible interpretations for the mereological pronoun it in (12), where the indeterminate (p-underspecified) interpretation $x \triangleleft(e n \oplus b x)$ is to be understood as a disjunctive interpretation covering all possible referents: the engine, the boxcar, or the two combined.

(15) a. the engine E2, en

b. the boxcar, $b x$

c. the composite object formed by hooking up the engine and the boxcar, en $\oplus b x$

d. or a $p$-underspecified interpretation, $x \triangleright(e n \oplus b x)$

According to Poesio et al., the merged interpretation (the entity formed by the engine and the boxcar) is the result of actions discussed in the text. Examples such as (12) and (16) have in common that they describe situations (attaching objects together or loading an object into another object) with a specific plan in mind; i.e., moving those objects from one place to another location. Therefore, the existence of a plan is crucial since it makes all alternative interpretations equivalent as far as the plan is concerned. For example, all the interpretations for the pronoun that in (16) will be equivalent and will achieve the same results because "once the two antecedents are joined, if one gets moved the other will get moved, too.” (2005: 11) 
(16) 26.1 S: okay

27.1 M: so then we'll

27.2 ... we'll be in position to

27.3 load the orange juice into the tanker car

$27.4 \quad$... and send that off

Based on these experimental findings, they proposed the Justified Sloppiness Hypothesis.

(17) The Justified Sloppiness Hypothesis: Ambiguous anaphoric expressions are not perceived as infelicitous provided that conditions a-c hold:

a) Both explicitly mentioned potential antecedents $x$ and $y$ are elements of an underlying mereological structure with summum $\sigma=x \oplus y$ which has been explicitly constructed (and made salient) in the dialogue; i.e., $\sigma=e n \oplus b x$ in (12).

b) The existence of this structure makes it possible to construct a p-underspecified interpretation in which the anaphoric expression is interpreted as denoting an element $z$ included in the mereological structure; i.e., part of its summum $\sigma$. In Poesio et al. (2005) this is modeled as a Discourse Representation Structure (DRS) (Kamp and Reyle 1993) in Figure 1.

c. All possible interpretations $(x, y, z, x \oplus y)$ are equivalent for the purposes of the plan.

\begin{tabular}{|l|}
\hline $\mathrm{x} \mathrm{y} \sigma \mathrm{z}$ \\
\hline$\cdots$ \\
$\sigma=\mathrm{x} \oplus \mathrm{y}$ \\
$\mathrm{z} \triangleleft^{*} \sigma$ \\
$\cdots$ \\
\hline
\end{tabular}

Figure 1: DRS showing a mereological structure (Poesio et al. 2005).

In all the examples analyzed in these investigations, the sum interpretation appeared with explicit predicates that make salient a mereological interpretation for the pronoun (i.e., hook to $(x, y)$, load into $(x, y)$, separate from $(x, y))$. As the authors point out, the conjunction and may also play an important role in facilitating the merged interpretation: "We already know that single conjuncts of coordinated noun phrases are relatively inaccessible to subsequent singular 
reference." (2005: 12), which leads them to hypothesize that the sum reference is perhaps the only element of the underspecified interpretation that remains salient in the context of conjunction.

However, when underspecification involves abstract anaphors coreferring with (or referring to) antecedents other than noun phrases such as clauses, sentences or larger fragments of discourse, mereology construction processes are less transparent, though interlocutors still seem to resolve them effortlessly. The lack of explicit mereology-construction predicates and, in many cases, the lack of conjunctions and other explicit discourse connectives force hearers to rely on different strategies to obtain a complex abstract referent in order to resolve abstract anaphors. Even the presence of explicit cues in discourse may not be enough to warrant a mereological interpretation in complex abstract objects.

Consider (18), a short discourse consisting of several clauses; some of them subordinate clauses introduced by the complementizer que 'that' as either relative, adverbial, or nominal clauses.

(18) San Martín, bueno, es una figura que ha sido un protector realmente nuestro que independizó la patria, ... que dictó tantas medidas tan eficaces e inolvidables, que históricamente recordando, el presidente Balta pidió inclusive que nos concedieran el honor de sepultar acá sus restos. Sí, por eso todos los peruanos tenemos una verdadera veneración inolvidable por el generalísimo Don José de San Martín. ${ }^{14}$

'San Martín is, well, a leading figure who really was a protector to us, who made our country independent, ... who took so many effective and unforgettable steps that, historically, even President Balta requested the honor for us to bury his remains here. Yes, that is why all Peruvians adore supreme commander Don José de San Martín.'

The discourse is segmented in Table 1. The possible antecedents of the underspecified demonstrative anaphor eso are numbered 1 through 5 in the column labelled Antecedent; individual clauses and groups of clauses are labelled and numbered $\pi_{1} . . \pi_{\mathrm{n}}$ in the column Segment; and the column Referent shows the denotation of each possible antecedent, that is, atomic propositions, events, or complex abstract referents (sums of atomic propositions) represented with the symbol $\oplus$. Clause 5 , the clause containing the anaphor, is not a possible antecedent.

14 Source: Corpus de Referencia del Español Actual (CREA): Perú, Oral. 
Table 1: Possible interpretations for anaphor eso.

\begin{tabular}{|c|c|c|c|}
\hline Antecedent & Segment & Referent & Interpretation \\
\hline 1 & $\pi_{1}:$ & $\mathrm{K}_{1}$ & $\begin{array}{l}\text { San Martín es una figura que ha sido un protector } \\
\text { realmente nuestro... }\end{array}$ \\
\hline 2 & $\pi_{2}:$ & $\mathrm{K}_{2}$ & que independizó la patria... \\
\hline 3 & $\pi_{3}:$ & $\mathrm{K}_{3}$ & que dictó tantas medidas tan eficaces e inolvidables... \\
\hline 4 & $\pi_{1} . . \pi_{3}:$ & $\oplus \mathrm{K}_{1}-\mathrm{K} \pi_{3}$ & $\begin{array}{l}\text { San Martín es una figura que ha sido un protector } \\
\text { realmente nuestro, que independizó la patria, que dictó } \\
\text { tantas medidas tan eficaces e inolvidables... }\end{array}$ \\
\hline 5 & $\pi_{4}$ & $\mathrm{~K}_{4}$ & $\begin{array}{l}\text { que, históricamente recordando, el presidente Balta } \\
\text { pidió inclusive que nos concedieran el honor de sepultar } \\
\text { acá sus restos. }\end{array}$ \\
\hline- & $\pi_{5}:$ & - & $\begin{array}{l}\text { Sí, por eso todos los peruanos tenemos una verdadera } \\
\text { veneración por el generalísimo don José de San Martín. }\end{array}$ \\
\hline
\end{tabular}

In this example, the speaker explains the reasons why Peruvians adore the historical figure José de San Martín. The anaphor eso in the last utterance is underspecified in that it may well refer to any of the atomic propositions individually $\left(\mathrm{K} \pi_{1} . . \mathrm{K} \pi_{\mathrm{n}}\right)$, or to the result of integrating some, or all these atomic propositions into a complex abstract referent. The first step I proposed towards a resolution of an underspecified abstract anaphor, cf. (3i), involves the creation by the hearer of a complex abstract mental object with a mereological structure that includes all possible interpretations for the anaphor, and such a mereological structure is represented as a set. Upon processing the relevant stretch of discourse, the hearer proceeds to construct the complex abstract object that includes all atomic propositions that are suitable to be viable referents and, possibly, a summum or complex abstract referent. The mereological structure for the complex abstract object in discourse (18) is the set $\Sigma=\left\{K \pi_{1}, K \pi_{2}, K \pi_{3}, K \pi_{4}, \oplus\right.$ $\left.\mathrm{K} \pi_{1}-\mathrm{K} \pi_{3}\right\}$. In principle, this complex abstract object, a mental construct, includes all possible interpretations for the anaphor, that is, every element in the mereological structure, whether atomic or not, is a potential candidate antecedent/ referent for the anaphor.

The preferred and most natural interpretation for the anaphor in (18) is the sum interpretation of $K \pi_{1}, K \pi_{2}$ and $K \pi_{3}$ (possible antecedent \#4) as it groups together three plausible reasons that explain why Peruvians adore José de San Martín; i.e., he was a protector, he fought for the country's independence, he took many effective administrative steps. As it stands, the first three utterances constitute an enumeration of reasons, and the presence of the subordinating conjunction que helps us explain the hearers' preference for the sum interpretation $\oplus \mathrm{K} \pi_{1}-\mathrm{K} \pi_{3}$. In this line, we may hypothesize that atomic propositions are 
less accessible as referents when no conjunctions are present, and that the conjunction que would favor the sum interpretation, akin to the role played by the coordinating conjunction $y$ 'and' in conjoined noun phrases (cf. example [1]).

However, although introduced as a subordinate adverbial clause, atomic proposition $\mathrm{K}_{4}$ (possible antecedent \#5) does not seem to be a viable referent for the pronoun because it does not constitute a natural reason for Peruvians to adore San Martín; it is most naturally understood as a consequence or effect of the three previous utterances. Mereological structures alone cannot explain why some elements like subordinating conjunctions favor the sum or collective interpretation in some situations, while disfavor it in others. As I suggest in (3ii) above, the second step in the resolution of an underspecified abstract anaphor involves the inference by the hearer of a meaningful rhetorical connection among the propositions in the mereological structure of the complex abstract object. Some discourse particles will play an important role in facilitating meaningful connections, while other particles will not. In (18), atomic propositions $\mathrm{K} \pi_{1}$ through $\mathrm{K} \pi_{3}$ are rhetorically connected since they contribute, individually, to elaborate on the figure of San Martín. Taken together, they provide a meaningful coherent description of the most relevant accomplishments of this historical figure. Atomic proposition $\mathrm{K} \pi_{4}$ seems naturally disconnected from such an elaboration as it describes an ad hoc event that it is either not helpful in describing the character's accomplishments, or it is only marginally connected. Such meaningful connection among propositions involves recognizing the speaker's intention to provide a relevant description of the character, and to present such information in a precise way; i.e., a plan in Poesio et al.'s terminology.

In this example, the abstract anaphor is resolved only after the hearer has inferred that the propositions in the complex abstract referent $\oplus \mathrm{K} \pi_{1}-\mathrm{K} \pi_{3}$ are rhetorically connected via the relation Elaboration. However, an important question remains unanswered: how do hearers integrate the propositional content into meaningful coherent discourse units? I argue that the theoretical framework of Segmented Discourse Representation Theory, henceforth SDRT, can explain this process.

\section{Inferring rhetorical relations in complex abstract antecedents}

The work by Mann and Thompson (1988), and later Asher (1993), Asher and Lascarides (2003), Lascarides and Asher (2007) laid the foundations for a 
detailed and systematic approach to discourse organization and coherence based on rhetorical structure. Although research on the interplay among anaphora, underspecification, and discourse relations is scarce, the rhetorical structure of discourse provides the amount of textual structure needed to account for cases of anaphoric reference to entities beyond the noun phrase and, as I claim, to account for underspecification that involves reference to abstract objects such as events and propositions. ${ }^{15}$

\subsection{Segmented Discourse Representation Theory}

Different authors have claimed that discourse segmentation has a hierarchical structure (Grosz and Sidner 1986; Mann and Thompson 1988; Asher 1993). In the following paragraphs I introduce the basics about Segmented Discourse Representation Theory, and I will then go on to analyze some Spanish examples. SDRT suggests that the propositional content of discourse depends on a discourse structure consisting of rhetorical relations that connects the meaning of utterances. These rhetorical relations (also called discourse relations) describe the different roles propositions play in the global discourse content, and capture important generalizations on diverse discourse phenomena. This theory extends dynamic semantics by introducing rhetorical relations into the logical form of discourse, and having truth conditional effects that SDRT exploits to predict how the compositional semantic content becomes augmented as the discourse unfolds.

Discourse relations are binary and can be either coordinating or subordinating. Coordinating relations indicate a continuation of some discourse pattern such as, for example, Narration, while subordinating relations such as Elaboration or Explanation indicate a rupture of some discourse pattern. Consider example (19) showing how rhetorical structure is represented in SDRT. ${ }^{16}$ This discourse fragment has been segmented into constituent discourse units; the propositions denoted by the utterances are represented with the symbol ' $\mathrm{K} \pi_{\mathrm{n}}$ ' and have been numbered consecutively.

(19) $\pi_{1}$ John had a great evening last night. $K \pi_{1}$

$\pi_{2}$ He had a great meal. $\quad K \pi_{2}$

$\pi_{3}$ He ate salmon. $\quad \mathrm{K}_{3}$

$\pi_{4}$ He devoured lots of cheese. $\quad K \pi_{4}$

$\pi_{5}$ He then won a dancing competition. $K \pi_{5}$

15 See the work by Asher and Wang (2003) and Alves (2006) on anaphoric ambiguity involving rhetorical relations.

16 This example is from Asher and Lascarides (2003). 
Discourse structures are represented either as tree-like graphs or as Segmented Discourse Representation Structures, SDRS's henceforth. ${ }^{17}$ In the tree-like form, coordinating relations are represented as horizontal edges and subordinating relations as vertical ones in SDRT. Dashed edges mark the link between a complex constituent and its sub-constituents. The tree in Figure 2 (Asher and Lascarides 2003: 147) shows the basic features of the rhetorical structure of discourse (19). The node $\pi_{6}$, which branches out into $\pi_{2}$ and $\pi_{5}$, provides more detail about the event in $\left(\pi_{1}\right)$, and node $\pi_{7}$, which branches out into $\pi_{3}$ and $\pi_{4}$, provides more detail about the event in $\left(\pi_{2}\right)$. As shown in this graph, Elaboration relations are subordinating, and Narration relations are coordinating.

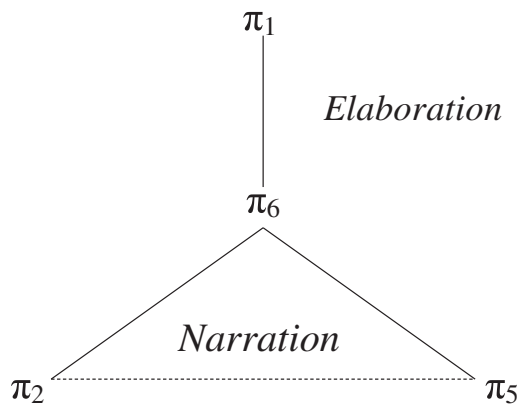

\section{Elaboration}

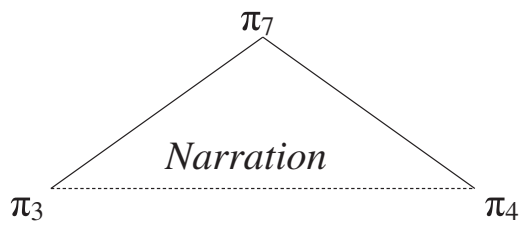

Figure 2: Graphic SDRS showing the rhetorical structure of discourse (12) (Asher and Lascarides 2003: 147).

Trees such as the one above are commonly represented as SDRS's such as the one in Figure 3 (Asher and Lascarides 2003: 140). For the remainder of this paper, I will represent discourse structures in the SDRS notation. A brief explanation on SDRS notation follows.

17 Segmented discourse representation structures follow the basic concept introduced by Kamp and Reyle (1993) in their discourse representation structures or DRS's extending the notation to include rhetorical relations. 


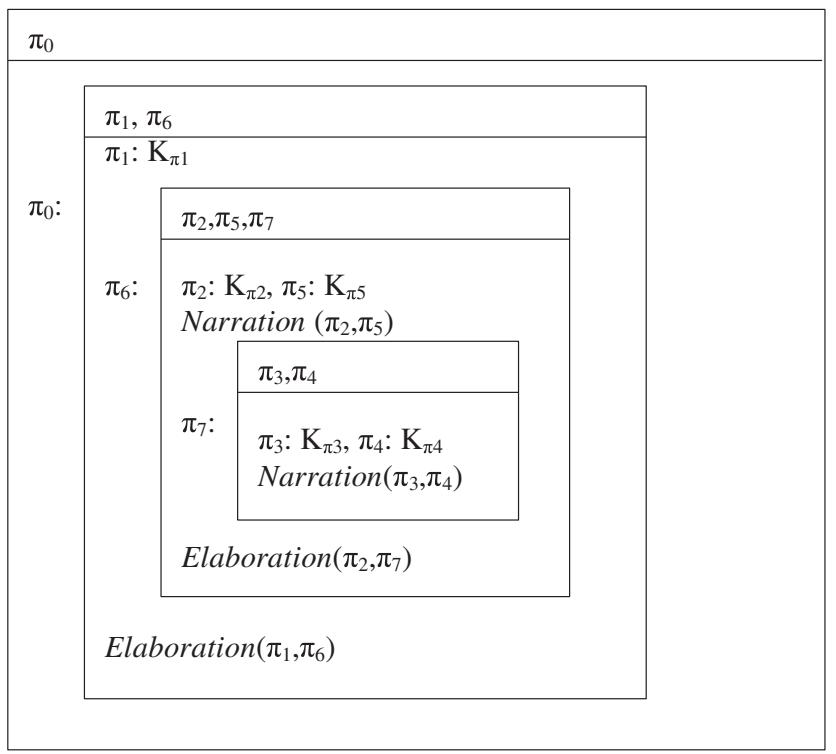

Figure 3: SDRS of discourse (19) (Asher and Lascarides 2003: 140).

Each box (each SDRS) consists of a set of referents in the upper part of the box and a set of conditions on the discourse referents; i.e., $\left\{\pi_{3} \pi_{4} \mid \operatorname{Narration}\left(\pi_{3}, \pi_{4}\right)\right\}$. Each discourse constituent is given a label $\pi_{n}$, and $K \pi_{n}$ stands for the proposition denoted by each individual constituent. The condition $\pi_{n}$ : K $\pi_{n}$ indicates that segment $\pi_{n}$ denotes the corresponding proposition $\mathrm{K} \pi_{n}$. Constituents $\pi_{6}$ and $\pi_{7}$ are just branching nodes in the structure representation, not actual utterances and, as such, they do not denote propositions. The SDRS $\pi_{0}$ is the initial SDRS having segments $\pi_{1}$ and $\pi_{6}$ in its universe, and these two constituents are connected via Elaboration (i.e., see the condition Elaboration $\left(\pi_{1}, \pi_{6}\right)$ in SDRS $\left.\pi_{0}\right)$. Note that SDRS's are nested to represent their recursive nature and the hierarchical structure of discourse: constituent $\pi_{6}$ opens a new SDRS with segments $\pi_{2}, \pi_{5}$ and $\pi_{7}$ in its universe; constituents $\pi_{2}$ and $\pi_{5}$ are linked via the coordinating relation Narration, and constituent $\pi_{7}$ opens a new SDRS with $\pi_{3}$ and $\pi_{4}$ in its universe.

\subsection{Coordinating relations and discourse topics in SDRT}

In SDRT, thematic integration at the propositional level creates a discourse topic (a proposition that summarizes the content of a series of atomic propositions in a specific stretch of discourse) under certain conditions. This was the case in discourse (2) (see RR3 in (4), where the hearer inferred a discourse topic from the 
complex abstract referent $\oplus K \pi_{1}-K \pi_{3}$. In this paper, I assume that the topic of the discourse, if any, is also a potential abstract referent for the abstract anaphor. If the topic constituent has not been explicitly introduced in the previous discourse, it must be constructed, that is, abstracted from the elements of the complex constituent it dominates. When that happens, the logical form of the topic constituent is updated every time the complex constituent is extended (Asher 2004).

The notion of discourse topic is important for certain coordinating rhetorical relations in SDRT such as Narration or Elaboration. Generally speaking, the rhetorical relation Narration can be defined as a relation between events that is responsible for the sequential progression in time typical of narrative discourse. SDRT's Narration relation entails temporal precedence. In (20), for example, the enrollment event $(e \alpha)$ temporally precedes the dropping event $(e \beta){ }^{18}$

(20) a. John enrolled in a German course but he dropped it.

b. $\operatorname{Narration}(\alpha, \beta) \rightarrow e_{\alpha} \prec e_{\beta}^{19}$

With regard to the temporal progression of discourse, events that elaborate on others are understood as temporally subordinate to them, whereas events that form a narrative with others follow each other. This idea was shown graphically with the Elaboration and Narration relations in Figure 2. Importantly, coordinating relations such as Narration, where constituents describe sequences of events, and Continuation require a topic, that is, a basic constituent that summarizes the contents of two related constituents, and that is linked to a complex constituent that contains them via the subordinating relation Elaboration. The need for a topic that summarizes the narrative is best illustrated with an example. The particle then is an overt signal of a narrative connection in (21a), yet this example is not fully coherent insofar as we do not know why the two events are connected together. As a result, the rhetorical connection between the two constituents is underspecified ?( $\alpha, \beta)$. In (21b), however, additional information is supplied that allows the narrative to be coherent; and the topic can be inferred: I got into trouble.

18 Because a given utterance can make more than one illocutionary contribution, a proposition can be the argument of several rhetorical relations in SDRT. Consider (20a), where the relations Narration and Contrast connect the two utterances. The Contrast relation is indicated by the particle but, whereas the temporal information (via Narration) is not signaled by any explicit marker and must be inferred via world-knowledge and common-sense reasoning.

19 This is an intentional simplification of SDRT's spatio-temporal consequence of the Narration relation, which entails an overlap between the post-state and pre-state of the events involved plus, possibly, the effect of a function that shifts the spatio-temporal location of its event argument (see Asher and Lascarides 2003 for further details). 
(21) a. I was running out of oxygen. Then my depth indicator died.

b. I was running out of oxygen. Then my depth indicator died and I knew I was in trouble.

The topic constraint on Narration (and other coordinating relations) is shown in

(22) (Asher and Lascarides 2003: 462):

(22) Topic constraint on Narration: $\phi$ Narration $(\alpha, \beta) \Rightarrow \neg \square(K \alpha \sqcap K \beta)$, i.e., $\alpha$ and $\beta$ share a contingent, common topic (and the more informative the topic, the better the narration). ${ }^{20}$

\subsection{Resolving underspecified abstract anaphors}

After having introduced the theoretical background needed to account for the resolution of underspecified abstract object anaphors, an analysis of a few natural examples is offered in the following paragraphs. The first example to be analyzed is discourse (23), segmented into its constituent clauses in Table 2.

Table 2: Possible interpretations for anaphor aquella hazaña.

\begin{tabular}{|c|c|c|c|}
\hline Antecedent & Segment & Referent & Interpretation \\
\hline 1 & $\Pi_{1}:$ & $\mathrm{e}_{1}, \mathrm{~K} \pi_{1}$ & $\begin{array}{l}\text { Desde el punto de vista tecnológico, la llegada } \\
\text { del hombre a la Luna proporcionó un tirón } \\
\text { industrial de gran magnitud a los EE.UU., }\end{array}$ \\
\hline 2 & $\pi_{2}:$ & $\mathrm{K}_{2}$ & $\begin{array}{l}\text { que de otra manera hubiera tardado varios años } \\
\text { en llegar. }\end{array}$ \\
\hline 3 & $\pi_{3}:$ & $\mathrm{K}_{3}$ & $\begin{array}{l}\text { Las empresas americanas de computadores, nuevos } \\
\text { materiales, aeronáutica y comunicaciones } \\
\text { recogieron inmediatamentelos beneficios de los } \\
\text { viajes lunares }\end{array}$ \\
\hline 4 & $\pi_{4}:$ & $\mathrm{K}_{4}$ & y se pusieron a la cabeza en el ranking mundial. \\
\hline \multirow[t]{2}{*}{5} & $\pi_{1} . . \pi_{4}$ & $\oplus \mathrm{K} \pi_{1}-\mathrm{K}_{4}$ & $\begin{array}{l}\text { Desde el punto de vista tecnológico [...] y se pusieron a la } \\
\text { cabeza en el ranking mundial. }\end{array}$ \\
\hline & $\pi_{5}:$ & & $\begin{array}{l}\text { Con respecto a los restantes países, aquella hazaña } \\
\text { constituyó el auténtico pistoletazo de salida después } \\
\text { del cual los más avanzados apostaron decididamente por } \\
\text { el desarrollo de una potente industria espacial. }\end{array}$ \\
\hline
\end{tabular}

20 The symbol ' $\Pi$ ' defines an operation that computes the common content or summary of two formulas, and the modal operator ' $\square$ ' represents logical necessity. 
(23) Desde el punto de vista tecnológico, la llegada del hombre a la Luna proporcionó un tirón industrial de gran magnitud a los EE.UU., que de otra manera hubiera tardado varios años en llegar. Las empresas americanas de computadores, nuevos materiales, aeronáutica, comunicaciones, etc., recogieron inmediatamente los beneficios de los viajes lunares y se pusieron a la cabeza en el ranking mundial. Con respecto a los restantes países, aquella hazaña constituyó el auténtico pistoletazo de salida después del cual los más avanzados apostaron decididamente por el desarrollo de una potente industria espacial. ${ }^{21}$

'From a technological point of view, the arrival of man on the Moon brought about an industrial stimulus of great magnitude in the US that otherwise would have taken several years longer to occur. American manufacturers of computers, new materials, aeronautics, and communication companies immediately reaped the benefits of the Moon missions, and moved to the top in world rankings. With regard to other countries, that great achievement signaled the start of a race in which the most advanced ones firmly gambled on developing a powerful space industry.'

The anaphoric expression in the last utterance is underspecified insofar as it may corefer with the event denoted by the noun phrase la llegada del hombre a la Luna 'the arrival of men on the Moon', $\mathrm{e}_{1}$, or with any of the atomic propositions $\mathrm{K} \pi_{1}, \mathrm{~K}_{3}, \mathrm{~K} \pi_{4}$ individually. These atomic propositions explain the direct consequences of the Moon landing to the US economy. Another potential referent is the complex abstract referent $\oplus \mathrm{K} \pi_{1}-\mathrm{K} \pi_{4}$. In the first step towards abstract anaphor resolution, the hearer creates the complex abstract object with mereological structure $\Sigma=\left\{\mathrm{e}_{1}, \mathrm{~K} \pi_{1}, \mathrm{~K} \pi_{2}, \mathrm{~K} \pi_{3}, \mathrm{~K} \pi_{4}, \oplus \mathrm{K} \pi_{1}-\mathrm{K} \pi_{4}\right\}$

In the second step, the hearer goes on to find a meaningful rhetorical connection among the simple or complex referents in the complex abstract object. If a meaningful rhetorical connection can be inferred, that will be the preferred interpretation, and the anaphor will be resolved. In this example, a connection can be established among propositions $\mathrm{K} \pi_{1}$ through $\mathrm{K} \pi_{4}$ (the complex abstract referent $\oplus K \pi_{1}-K \pi_{4}$ ), and the hearer can also infer a common topic of discourse from this complex abstract referent. The rhetorical inference and topic construction processes are shown in Figure 4, which has been simplified in order to show the most relevant information.

The common topic of discourse (the Moon landing had important consequences) is represented in the SDRS with the symbol $\pi$ (without a subscript). The topic $(\pi)$, a

21 Source: Corpus de Referencia del Español Actual (CREA): Ruiz de Gopequi, Luis. 1996. Hombres en el espacio. Pasado, presente y futuro. Madrid: McGraw-Hill. 


\begin{tabular}{|c|c|}
\hline \multicolumn{2}{|c|}{$\pi, \pi^{*}, \mathrm{z}$} \\
\hline \multirow{2}{*}{$\pi:$} & tex y n \\
\hline & $\begin{array}{l}\mathrm{e}: \mathrm{x} \text { boosts } \mathrm{y} \\
\text { Moon landing(x) } \\
\mathrm{US} \text { tech industry(y) } \\
\operatorname{loc}(e)=t \\
e \subseteq t \\
e \prec n\end{array}$ \\
\hline$\pi^{*}:$ & $\begin{array}{cc}\pi 1-\pi 2 & \pi 3-\pi 4 \\
\text { Continuation } & \text { Continuation }\end{array}$ \\
\hline $\begin{array}{l}\text { Elat } \\
\text { that } \\
\mathrm{z}=\text { ? }\end{array}$ & onement $(\mathrm{z})$ \\
\hline
\end{tabular}

Figure 4: SDRS showing the topic of discourse (23).

summary of the whole discourse, is built via a generalization operator (Asher 1993) from the semantic content of the constituent discourse segments $\pi_{1}$ through $\pi_{4}$. Topic construction is incremental: a representation of the topic content includes an eventuality that is a summary of the first two segments $\left(\pi_{1}\right.$ and $\left.\pi_{2}\right)$, and the resulting topic is then updated with the contents of the remaining segments.

An event (e: $x$ boosts y) results after processing segments $\pi_{1}$ and $\pi_{2}$. A time discourse referent $t$ is introduced in the universe of the sub-SDRS representing the topic $\pi$, and the function loc assigns to event $e$ the interval of time it occupies (time $t$ ). Upon processing the first two and subsequent segments, the hearer is able to construct a topic for the discourse that includes an event and, by processing the various past tenses in the discourse, a past time in which the event is located. This is shown with the SDRS condition $e^{\prec n}$. As for the rest of the SDRS, the sub-SDRS $\pi^{\star}$ is a complex segment resulting from all constituent segments in (23), which are connected by the Continuation relation. This complex segment elaborates on the topic via the subordinating relation Elaboration $\left(\pi, \pi^{\star}\right)$. Finally, the condition that achievement $(z)$ introduces the abstract anaphor in the SDRS and the condition $z=\pi^{*}$ indicates the discourse anaphoric link: there is a discourse referent $\mathrm{z}$ that is 'a great achievement' and such discourse referent is the complex segment $\pi^{\star}$, that is, the interpretation resulting from connecting segments $\oplus \pi_{1}-\pi_{4}$ rhetorically. The abstract anaphor is therefore resolved. 
Next, I present the analysis of discourse (18), repeated in Table 1. As it was explained in a previous section, this discourse explains why, according to the speaker, Peruvians praise the soldier and politician José de San Martín. In the first step towards abstract anaphor resolution the hearer creates a complex abstract object that includes all potential interpretations for the anaphor, the set with mereological structure $\Sigma=\left\{K \pi_{1}, K \pi_{2}, K \pi_{3}, K \pi_{4}, \oplus K \pi_{1}-K \pi_{3}\right\}$, and then seeks to establish a rhetorical connection among atomic propositions $\mathrm{K} \pi_{1}-\mathrm{K} \pi_{3}$. That connection is Continuation because the individual utterances introduce three individual, yet thematically connected, reasons that elaborate on the aforementioned historical figure. The merged interpretation is therefore the preferred interpretation.

Once the hearer has inferred a thematic relation among the propositions in the complex abstract referent, a topic for this stretch of discourse is created. As noted above for discourse (23), the initial discourse topic is built from the semantic contents of the first two propositions and it is further updated upon processing subsequent discourse segments. The SDRS in Figure 5 shows the

\begin{tabular}{|c|c|c|c|}
\hline \multicolumn{4}{|c|}{$\pi, \pi_{1}, \pi_{2}$} \\
\hline \multirow[t]{2}{*}{$\pi:$} & $x, e, t$ & \multirow[t]{2}{*}{$\pi_{1}:$} & $x, e_{1}, t_{1}, n$ \\
\hline & $\begin{array}{l}\text { e: important figure }(x) \\
\operatorname{Event}(e) \\
\operatorname{loc}(e)=t \\
e \subseteq t \\
t<n\end{array}$ & & $\begin{array}{l}\text { e: is our protector }(x) \\
\text { Event }\left(e_{1}\right) \\
\operatorname{San} \operatorname{Martín}(x) \\
\operatorname{loc}\left(e_{1}\right)=t_{1} \\
e_{1} \subseteq t_{l} \\
t_{l} \prec n\end{array}$ \\
\hline \multirow[t]{2}{*}{$\pi_{2}:$} & $z, y, e_{2}, t_{2}, n$ & & \\
\hline & $\begin{array}{l}\text { e: make independent }(z, y) \\
z=x \\
\text { Country }(y) \\
\text { Event }\left(e_{2}\right) \\
\operatorname{loc}\left(e_{2}\right)=t_{2} \\
e_{2} \subseteq t_{2} \\
t_{2}<n\end{array}$ & & \\
\hline & $\operatorname{pration}\left(\pi, \pi_{1}\right)$ & & \\
\hline
\end{tabular}

Figure 5: Initial SDRS showing the processing of segments $\pi, \pi_{1}$ and $\pi_{2}$ from discourse (18). 
initial processing of the discourse. SDRS $\pi_{0}$, the discourse initial SDRS, includes in its universe the referents $K \pi$ (the initial topic of discourse), $K \pi_{1}$ and $K \pi_{2}$.

The topic represented with the sub-SDRS $\pi$ is constructed by processing the semantic contents of $\pi_{1}$ and $\pi_{2}$ and it can be described schematically as there is an event/state $e$ and there is an $x$ such that $x$ is an important figure and protector in $e$. The event $e$ is temporally located at a past time $t$ that is inferred from the processing of the past tenses in $\pi_{1}$ and $\pi_{2}$.

Segment $\pi_{1}$ is an elaboration of the topic as indicated with the condition Elaboration $\left(\pi, \pi_{1}\right)$. Segments $\pi_{1}$ and $\pi_{2}$ are rhetorically connected via Continuation. This rhetorical relation will be visible in Figure 6.

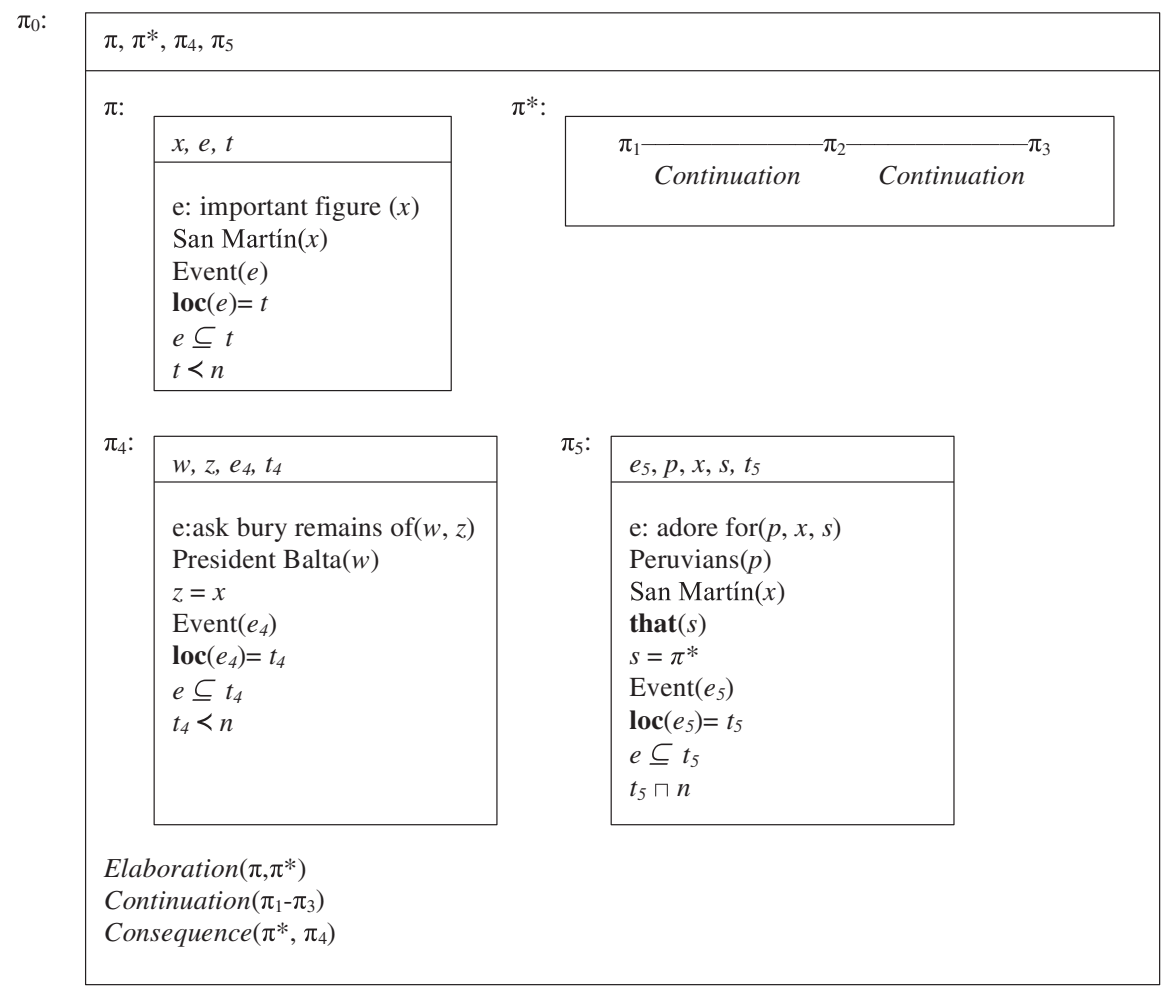

Figure 6: Simplified SDRS after processing $\pi_{1}-\pi_{5}$ in (18).

As other propositions in the complex abstract referent are processed, new discourse relations are inferred among the constituent segments, and the topic of the discourse is further enriched with this new information. Figure 6 reflects 
the updated discourse structure that results after having processed segments $\pi_{4}$ and $\pi_{5}$. The topic of the discourse $(\pi)$ has been updated with the new information: it now includes a discourse referent for the variable x (i.e., San Martín(x)). The sub-SDRS $\pi^{\star}$ reflects that constituents $\pi_{1}-\pi_{3}$ are connected via the relation Continuation, and the whole segment comprising $\pi_{1}-\pi_{3}$ is an Elaboration of the topic $\pi$ (i.e., Elaboration $\left(\pi, \pi^{\star}\right)$.

The contents of proposition $\mathrm{K} \pi_{4}$ are presented in the sub-SDRS $\pi_{4}$, and the rhetorical connection with the previous three segments is indicated with the condition Consequence $\left(\pi^{\star}, \pi_{4}\right)$. This condition indicates that proposition $\mathrm{K} \pi_{4}$ is not part of the merged interpretation $\oplus \mathrm{K} \pi_{1}-\mathrm{K} \pi_{3}$, hence, it is not an acceptable referent to the abstract anaphor. Finally, segment $\pi_{5}$ is also modeled as a subSDRS that includes the underspecified anaphor eso ('that'), now resolved. The condition that(s) introduces the anaphor in the sub-SDRS and the identity condition $\mathrm{S}=\pi^{\star}$ indicates that the referent of the demonstrative pronoun is the merged interpretation of propositions $K \pi_{1}-K \pi_{3}$ rhetorically connected via the coordinating relation Continuation.

As we have seen in this paper, some interesting analogies can be drawn between the postulates of the Justified Sloppiness Hypothesis for nominal antecedents and my proposal on abstract object anaphor resolution. As I have claimed, the abstract object created by the hearer in the first step towards anaphor resolution has a mereological structure that includes all the potential candidate referents of the underspecified anaphor. In semantic terms, the complex abstract object may possibly include a summum (a complex abstract referent such as $\pi^{\star}$ in Figure 6) as well as all parts of the summum (atomic propositions). In my view, this level of granularity is adequate since complex abstract referents are possible but not necessary. As I argue in (3ii), when hearers cannot infer a rhetorical relation among propositions in the mereological structure, they go back to the set and find a suitable referent to resolve the anaphor: any of the atomic propositions in the mereological structure. However - provided that they are availablecomplex abstract referents are preferred over atomic propositions as the most salient interpretation simply because they are generally interpreted as part of a general purpose by the speaker (a plan in Poesio et al.'s terminology), in addition to contributing to the thematic coherence of discourse.

We have seen that the notion of a plan proposed in the Justified Sloppiness Hypothesis, needed to account for the merged interpretation of noun phrases finds an analogue in merged interpretations at the propositional level. Here, I argue that thematic coherence at the propositional level is best accomplished by proposing certain relations at the highest level of rhetorical structure. While plans are usually conceived of as denoting event or action types (Poesio et al. 2007), specific rhetorical relations like Narration and Continuation can also be conceived of as 
sets of events. Thus, for example, the Continuation relation $\pi^{\star}$ in Figure 6 would denote the set of events that elaborate on the historical figure of San Martín:

$$
\pi^{\star}=\left\{e^{\prime} \mid \exists x, y, z e^{\prime}: \text { Continuation }\left(e_{x}, e_{y}, e_{z}\right)\right\}
$$

In addition, in order to maintain an adequate level of granularity in the mereological structure I will adopt Poesio et al.'s part-of relation between plans (2007: 19). This will allow me to account for other potential - though less salient- referents to the abstract anaphor within the complex abstract referent. Thus, $K \pi_{\mathrm{n}}$ (any of the atomic propositions that are part of $\pi^{\star}$ ) is a subset of $K \pi^{\star}$, and the symbol $\triangleleft$ defines the 'part-of' relation between propositions, whereas the symbol $\subseteq$ stands for event inclusion, namely: for every event $e$ in $\mathrm{K} \pi_{\mathrm{n}}$ there is an event $e^{\prime}$ in $\mathrm{K}^{\star}$ such that $e \subseteq e^{\prime}$.

$$
\mathrm{K} \pi_{\mathrm{n}} \triangleleft \mathrm{K} \pi^{\star} \equiv\left[\forall e \in \mathrm{K} \pi_{\mathrm{n}} \exists e^{\prime} \in \mathrm{K} \pi^{\star} \wedge e \subseteq e^{\prime}\right]
$$

\section{Conclusions}

I propose that mereological interpretations are appropriate to account for cases of referential underspecification involving higher-order entities in discourse. Following previous work on reference to abstract objects in discourse, I argue that merged interpretations of propositional material can be adequately modelled following mereological processes analogous to the ones proposed for noun phrase antecedents. Propositional mereological structures include all possible interpretations, that is, all potential atomic propositional referents and, possibly, a summum interpretation that is the result of merging all the relevant propositional referents into a complex abstract referent. Following the proposal for mereological noun phrase antecedents set forth in the Justified Sloppiness Hypothesis, mereological abstract anaphoric expressions (i.e., pronouns or NP anaphors) are interpreted as denoting an element $z$ included in the propositional mereological structure. However, the summum interpretation will be the most salient of all candidate interpretations as long as hearers can infer a meaningful rhetorical connection among some (or all) of the utterances involved in the relevant stretch of discourse. Such a specific rhetorical connection is Elaboration, and the utterances that provide such elaboration are commonly connected via Narration or Continuation relations.

According to SDRT's proposal, certain relations among utterances facilitate merged interpretations better than others. For example, coordinating relations such as Narration or Continuation are better suited to that purpose 
as they represent a thematic continuation instead of a thematic disruption. The merged (or summum) interpretation inferred creates a topic of discourse (a constituent that summarizes the contents of the propositions connected) that is updated as new material is added to the Narration or Continuation. Based on these premises and on my observation of natural Spanish discourse, my hypothesis is that hearers carry out a complex cognitive process in order to resolve abstract object underspecification. ${ }^{22}$ This process would involve three steps: (i) creation of a complex abstract object - a purely mental construct - with mereological structure; (ii) an inferential process whereby hearers infer feasible rhetorical relations among the propositions in the mereological structure and, finally, (iii) a process of preferred referent identification that resolves the anaphor.

With regard to future research on the construction of complex abstract referents, further investigation is needed on the important role that certain discourse connectives and discourse markers may play in mereological interpretations, and in the thematic integration and overall cohesion of discourse. As elements that contribute to the formation of rhetorical relations, discourse particles may play a crucial role in helping resolve anaphoric underspecification at the propositional level. Another significant line of investigation may include the different referential properties of abstract object anaphors; i.e., noun phrases, pronouns, demonstratives, in facilitating summum interpretations. Finally, some empirical investigation in the form of psychological research on anaphoric reference and underspecification of multi-sentence antecedents would greatly contribute to our current understanding of text coherence and interpretation. ${ }^{23}$

22 It may be argued that the resolution process for complex abstract objects put forth in this paper is too complex given the overgeneralization and simplification entailed by the Justified Sloppiness Hypothesis. In my view, the three steps involved in the resolution process are justified insofar as some kind of coherence formation and integration process is needed by hearers when they are presented with multiple -possibly discontinued and disrupted- discourse segments. I believe that my proposal is not any more complex than other proposals that call for inferential processes that recognize causal relations among events in multi-sentence discourses.

23 See Versley (2008) for a detailed study on referential ambiguity, and Recasens et al. (2014) on the notion of near-identity. Although these studies do not specifically address underspecification involving collections of events or propositions they can be seen as a good point of departure for annotation efforts and empirical exploration on multi-sentence antecedents. 


\section{References}

Albrecht, Jason E. \& Charles Clifton. 1998. Accessing singular antecedents in conjoined phrases. Memory and Cognition 26(3). 599-610.

Alves, Ana T. 2006. Anaphoric temporal locators and discourse structure. In Beáta Gyuris, László Kálmán, Chris Piñón \& Károly Varasdi (eds.), Proceedings of the ninth symposium on logic and language (LOLA9), 24-26. Budapest: Eötvös Loránd University.

Artstein, Ron \& Massimo Poesio. 2006. Identifying reference to abstract objects in dialogue. In David Schlangen \& Raquel Fernández (eds.), Proceedings of brandial 2006: The 10th workshop on the semantics and pragmatics of dialogue, Potsdam, Germany, September 11 -132006, 56-63. Potsdam: University of Potsdam.

Asher, Nicholas. 1993. Reference to abstract objects in discourse. Dordrecht: Kluwer.

Asher, Nicholas. 2004. Discourse topic. Theoretical Linguistics 30. 161-201.

Asher, Nicholas \& Alex Lascarides. 2003. Logics of conversation. Cambridge: Cambridge University Press.

Asher, Nicholas \& Linton Wang. 2003. Ambiguity and anaphora with plurals in discourse. In Robert B Young \& Yuping Zhou (eds.), Proceedings from semantics and linguistic theory XIII (SALT XIII), 19-36. Ithaca, NY: Cornell University.

Blakemore, Diane. 2002. Relevance and linguistic meaning: The semantics and pragmatics of discourse markers. Cambridge: Cambridge University Press.

Byron, Donna K. 2002. Resolving pronominal reference to abstract entities. Proceedings of the 40th annual meeting of the association for computational linguistics (ACL-02). 80-87. https://doi.org/10.3115/1073083.1073099.

Byron, Donna K. 2003. Annotation of pronouns and their antecedents: A comparison of two domains. Technical report 703. Rochester, NY: The University of Rochester.

Dipper, Stefanie \& Heike Zinsmeister. 2012. Annotating abstract anaphora. Language Resources and Evaluation 46(1). 37-52.

Eckert, Miriam \& Michael Strube. 2000. Dialogue acts, synchronizing units and anaphora resolution. Journal of Semantics 17(1). 51-89.

Filik, Ruth, Anthony J Sanford, Patrick Sturt \& Massimo Poesio. 2005. Underspecification in anaphoric reference to structured entities. Paper presented at AMLaP 2005, 11th Annual Conference on Architectures and Mechanisms for Language Processing, University of Gent, 5-7 September.

Gross, Derek, James F Allen \& David R Traum. 1993. The TRAINS 91 dialogues. TRAINS technical note 92-1. Rochester, NY: The University of Rochester.

Grosz, Barbara J \& Candace L Sidner. 1986. Attention, intentions and the structure of discourse. Computational Linguistics 12(3). 175-204.

Hankamer, Jorge \& Ivan Sag. 1976. Deep and surface anaphora. Linguistic Inquiry 7(3). 391-426.

Hobbs, Jerry R., Mark Stickel, Douglas E. Appelt \& Paul Martin. 1993. Interpretation as abduction. Artificial Intelligence 63(1-2). 69-142.

Kamp, Hans \& Uwe Reyle. 1993. From discourse to logic: Introduction to model-theoretic semantics of natural language, formal logic and discourse representation theory. Dordrecht: Kluwer.

Karttunen, Laurie. 1976. Discourse referents. In James McCawley (ed.), Syntax and semantics, vol. 7, New York: Academic Press. 
Lascarides, Alex \& Nicholas Asher. 2007. Segmented discourse representation theory: Dynamic semantics with discourse structure. In Harry Bunt \& Reinhard Muskens (eds.), Computing meaning, vol. 3, 87-124. Dordrecht: Springer.

Link, Godehard. 1983. The logical analysis of plurals and mass terms: A lattice-theoretical approach. In Paul Portner \& Barbara H Partee (eds.), Formal semantics: The essential readings, 127-147. Oxford: Blackwell.

Lyons, John. 1977. Semantics. Cambridge: Cambridge University Press.

Mann, William C \& Sandra A Thompson. 1988. Rhetorical structure theory: Toward a functional theory of text organization. Text 8(3). 243-281.

Moxey, Linda M., Anthony J Sanford, Patrick Sturt \& Lorna Morrow. 2004. Constraints on the formation of plural reference objects: The influence of role, conjunction and the type of description. Journal of Memory and Language 51. 346-364.

Müller, Christoph. 2008. Fully automatic resolution of it, this and that in unrestricted multiparty dialog. Tübingen: University of Tübingen dissertation.

Nakhimovsky, Alexander. 1988. Aspect, aspectual class and the temporal structure of narrative. Computational Linguistics 14(2). 29-43.

Navarretta, Costanza \& Sussi Olsen. 2009. The annotation of pronominal abstract anaphora in Danish texts and dialogues. DAD Report 1, Center for Language Technology, University of Copenhagen.

Ojeda, Almerindo. 1993. Linguistic individuals. Stanford, CA: CSLI Publications.

Pinkal, Manfred. 1996. Vagueness, ambiguity and underspecification. In Teresa Galloway \& Justin Spence (eds.), Proceedings of SALT VI, 185-201. Ithaca, NY: Cornell University.

Poesio, Massimo \& Ron Artstein. 2008. Anaphoric annotation in the ARRAU corpus. In Proceedings of the Sixth International Conference on Language Resources and Evaluation (LREC-08), 1170-1174.

Poesio, Massimo, Uwe Reyle \& Rosemary Stevenson. 2007. Justified sloppiness in anaphoric reference. In Harry Bunt \& Reinhard Muskens (eds.), Computing meaning, vol. 3, 11-31. Dordrecht: Springer.

Poesio, Massimo, Patrick Sturt, Ron Artstein \& Ruth Filik. 2005. Underspecification and anaphora: Theoretical issues and preliminary evidence. CS Technical Report CSM-438. University of Essex. http://cswww.essex.ac.uk/Research/nle/arrau/

Recasens, Marta \& María A Martí. 2010. AnCora-CO: Coreferentially annotated corpora for Spanish and Catalan. Language Resources and Evaluation 44(4). 315-345.

Recasens, Marta, María A Martí \& Mariona Taulé. 2007. Text as scene: Discourse deixis and bridging relations. Procesamiento del Lenguaje Natural 39. 205-211.

Recasens, Marta, María A Martí \& Liliana Tolchinsky. 2014. Coreference is not always either/or: Psycholinguistic evidence for near-identity. Language, Cognition and Neuroscience 29(7). 844-855.

Schuster, Ethel. 1986. Towards a Computational Model of Anaphora in Discourse: Reference to Events and Actions. School of Engineering and Applied Science, University of Pennsylvania. Technical Reports (CIS), Department of Computer and Information Science Technical Report No. MS-CIS-86-34. https://repository.upenn.edu/cis_reports/642/

Ter Meulen, Alice. 1984. Events, quantities and individuals. In Johan Van Benthem \& Alice ter Meulen (eds.), Generalized quantifiers in natural language, 259-279. Dordrecht: Foris.

Vendler, Zeno. 1967. Linguistics in philosophy. Ithaca, NY: Cornell University Press.

Versley, Yannick. 2008. Vagueness and referential ambiguity in a large-scale annotated corpus. Research on Language and Computation 6(3). 333-353. 
Vossen, Piek (ed.). 1998. A multilingual database with lexical semantic networks: The EuroWordNet database. Dordrecht: Kluwer.

Webber, Bonnie L. 1979. A Formal approach to discourse anaphora. New York: Garland.

Webber, Bonnie L. 1988. Discourse deixis: Reference to discourse segments. Proceedings of the 26th Annual Meeting of the Association for Computational Linguistics. 113-122.

Webber, Bonnie L., Matthew Stone, Aravind Joshi \& Alistair Knott. 2003. Anaphora and discourse structure. Computational Linguistics 29(4). 545-587. 